\title{
PERANCANGAN MULTIDIMENSIONAL SCALLING METRIK DENGAN GUI PYTHON 3.8 UNTUK KLASIFIKASI PROGRAM KELUARGA BERENCANA
}

\author{
${ }^{1}$ Bramesa Winanda Nugraha, ${ }^{2}$ Tatik Widiharih, ${ }^{3}$ Puspita Kartikasari \\ ${ }^{1,2,3}$ Departemen Statistika, FSM Universitas Diponegoro \\ Email: bramesaw@ student.undip.ac.id
}

\begin{abstract}
ABSTRAK
Program KB (Keluarga Berencana) merupakan suatu bentuk upaya yang dilakukan oleh pemerintah untuk mengendalikan banyaknya kuota penduduk. Program KB selalu dikaitkan dengan alat kontrasepsi sebagai kendaraan untuk menyukseskan program tersebut. Metode kontrasepsi dibagi menjadi dua yaitu jangka panjang (MKJP) yang meliputi Intra Uterine Device, Implan, Metode Operasi Wanita dan Metode Operasi Pria dan jangka pendek (Non MKJP) yang meliputi Suntik, Kondom, dan Pil. Penelitian ini bertujuan untuk memetakan Kabupaten/Kota di Jawa Tengah berdasarkan metode kontrasepsi yang digunakan oleh peserta KB dalam dua dimensi. Metode pemetaan yang digunakan adalah Multidimensional Scaling Metrik dengan membangun suatu program berbasis Graphical User Interface (GUI) Python. Hasil penelitian ini memvisualisasikan karakteristik dari peserta KB pada Kabupaten/Kota berdasarkan jenis dan metode kontrasepsi yang digunakan. Pada kuadran I memiliki karakteristik penggunaan Non MKJP. Kuadran II memiliki karakteristik penggunaan PIL. Kuadran III merupakan kelompok dengan tingkat penggunaan kontrasepsi yang rendah baik MKJP maupun Non MKJP. Kuadran IV memiliki karakteristik penggunaan IUD. Dengan kriteria perceptual map yang dihasilkan sempurna, ditunjukan oleh nilai stress sebesar $0.4 \%$.
\end{abstract}

Kata kunci: Program KB, GUI Python, Multidimensional Scalling, Metrik.

\section{PENDAHULUAN}

Indonesia merupakan negara dengan kuota penduduk terbesar dan terbanyak keempat di dunia. Sensus Penduduk pada tahun 2010, BPS mencatat bahwa jumlah penduduk Indonesia mencapai 237.641.326 jiwa, sementara kecepatan pertumbuhan penduduk di Indonesia sebesar 1,49 persen per tahun. Banyak faktor yang mempengaruhi hal tersebut, salah satunya adalah fertilitas, karena fertilitas adalah faktor tingginya angka kelahiran [1]. Bentuk upaya yang dilakukan dan diterapkan oleh Pemerintah Indonesia untuk mengatasi masalah pengendalian jumlah penduduk adalah dengan mengadakan program
Keluarga Berencana (KB) yang dicanangkan oleh Badan Kependud ukan dan Keluarga Berencana [2].

Pemilihan metode kontrasepsi yang dianjurkan pemerintah yang tepat dan sesuai dengan kebutuhan dan kondisi, dapat mengurangi kecepatan pertumbuhan penduduk di Indonesia. Menurut BKKBN [3] jangka waktu pemakaian metode kontrasepsi dibagikan menjadi dua metode, yaitu metode kontrasepsi jangka Panjang (MKJP) dan metode kontrasepsi jangka pendek (Non MKJP). Metode Kontrasepsi Jangka Panjang (MKJP) terdiri atas Intra Uterine Device (IUD), Implan, Metode Operasi Wanita (MOW) dan Metode Operasi Pria (MOP), sedangkan Metode kontrasepsi 
jangka pendek (Non MKJP) terdiri dari Suntik, Kondom, dan Pil. Penggunaaan metode kontrasepsi jangka panjang di Indonesia masih kurang. Kecenderungan ini terjadi sejak tahun 1987. Sesuai rekomendasi Badan Kependudukan dan Keluarga B erencana Nasional (BKKBN) di Provinsi Jawa Tengah dari hasil Narasi Rapat Pengendalian Program dan Anggaran Data BKKBN 2018 untuk memberikan dampak yang signifikan pada pencapaian peserta KB maka penggarapan pelayanan KB diprioritaskan pada wilayah MKJP (Metode Kontrasepsi Jangka Panjang) yang rendah.

Dalam melakukan pemetaan untuk mengatasi permasalahan tersebut dapat menggunakan metode Multidimensional Scaling. Multidimensional Scaling merupakan metode yang tepat untuk melakukan analisis pada permasalahan tersebut karena tujuan dari analisis Multidimensional Scaling pada penelitian ini adalah untuk memetakan kabupaten/kota(objek) dan metode kontrasepsi(variabel) dalam satu bidang multidimensi sehingga dapat diketahui karakteristik peserta KB aktif berdasarkan metode kontrasepsi (variabel) yang digunakan pada kabupaten/kota(objek) di Provinsi Jawa Tengah. Penelitian mengenai penerapan Multidimensional Scaling juga dilakukan oleh [4] dengan menggunakan Multidimensional Scaling metrik pada program $\mathrm{R}$ yang dapat mengetahui karakteristik kemiskinan di Provinsi Banten dengan nilai stress cukup baik. Penelitian tersebut juga sekaligus menunjukkan bahwa selain menggunakan SPSS, penerapan Multidimensional Scaling juga dapat dilakukan menggunakan program statistical software lainnya seperti $\mathrm{R}$ dan Python.

Berdasarkan penjelasan diatas, maka dalam penelitian akan dilakukan dengan menggunakan analisis Multidimensional Scaling metrik dengan komputasi
Graphical User Interface (GUI) Program Python 3.8. Komputasi Graphical User Interface (GUI) tersebut memiliki kelebihan yaitu mempermudah penggunanya dalam proses analisis, memberikan gambaran data secara visual berupa plot objek, plot variabel dan plot joint. Selain itu, GUI dapat menampilkan hasil perhitungan yang akurat dan sistematis sehingga memudahkan pengguna dalam mempelajari Multidimensional Scaling metrik.

\section{METODOLOGI PENELITIAN \\ Sumber Data dan Variabel Penelitian}

Data yang akan digunakan pada penulisan kegiatan tugas akhir ini adalah data sekunder tentang "Persentase Peserta KB Aktif menurut Metode Kontrasepsi Kabupaten/Kota di Provinsi Jawa Tengah Bulan Januari sampai Desember 2019" yang diperoleh dari website Badan Kependudukan Keluarga Berencana Nasional Provinsi Jawa Tengah (https://aplikasi.bkkbn.go.id/sr/DA LLAP/Laporan2013/Bulanan/Dalap2013Ta bel15 .aspx). Software yang digunakan dalam analisis ini adalah GUI Python 3.8.

Terdapat tujuh variable penelitian yaitu IUD (Intra Uterinece Devices) ( $\left.\mathrm{X}_{1}\right)$, MOW (Metode Operasi Wanita) $\left(\mathrm{X}_{2}\right)$, MOP (Metode Operasi Pria) $\left(\mathrm{X}_{3}\right)$, Kondom $\left(\mathrm{X}_{4}\right)$, Implan $\left(\mathrm{X}_{5}\right)$, Suntikan $\left(\mathrm{X}_{6}\right)$, Pil $\left(\mathrm{X}_{7}\right)$ dalam persen.

\section{Metode Analisis Data}

Analisis data menggunakan tahaptahap sebagai berikut:

1. Mentukan matriks Do (D objek) dengan jarak euclidean

2. Menentukan matriks Bo (B objek)

3. Menentukan koordinat objek dengan menggunakan eigen values serta eigen vector dari matriks Bo

4. Mentukan matriks Dv (D variabel) dengan jarak euclidean

5. Menentukan matriks Bv 
6. Menentukan koordinat variable dengan menggunakan eigen values dan eigen vector matriks $\mathrm{Bv}$

7. Menggabungkan perceptual map objek dan preceptual variabel kedalam satu perceptual map

8. Menghitung matriks disparaties

9. Menghitung nilai stress

10. Interpretasi

\section{HASIL DAN PEMBAHASAN}

\section{Analisis Multidimensional Scaling Metrik dengan GUI Python 3.8}

1. Menentukan matriks Do (D objek) dengan jarak euclidean

Hasil jarak Euclidean dari matriks

Do35x35 :

Do $=\left[\begin{array}{ccccc}0 & 12.143 & \cdots & 25.788 & 24.226 \\ 12.143 & 0 & \cdots & 24.783 & 20.895 \\ \vdots & \vdots & \ddots & \vdots & \vdots \\ 25.788 & 24.783 & \cdots & 0 & 6.789 \\ 24.226 & 20.895 & \cdots & 6.789 & 0\end{array}\right]$

Matriks jarak Do membuktikan

bahwa Kabupaten Kudus dan

Kabupaten Brebes memiliki jarak yang dekat dengan nilai sebesar 2.644 persen. Hal tersebut mengindikasikan Kabupaten Kudus dan Kabupaten Blora terdapat kesamaan berdasarkan karakteristik penggunaan metode kontrasepsi pada peserta KB aktif diantara Kabupaten atau Kota yang lainnya. Sedangkan Kota Magelang dan Kabupaten Jepara memiliki jarak terjauh dengan nilai sebesar 45.909 persen. Hal ini mengindikasikan bahwa Kota Magelang dan Kabupaten Jepara memiliki ketakmiripan karakteristik penggunaan metode kontrasepsi pada peserta KB aktif diantara Kabupaten atau Kota yang lainnya.

2. Menentukan matriks Bo. Diperoleh hasil matriks Bo :

Bo=

$$
\left[\begin{array}{ccccc}
316.55 & 195.122 & \cdots & -117.309 & -112.807 \\
195.122 & 221.140 & \cdots & -139.606 & -85.380 \\
\vdots & \vdots & \ddots & \vdots & \vdots \\
-117.309 & -139.606 & \cdots & 113.857 & 56.244 \\
-112.807 & -85.380 & \cdots & 56.244 & 44.721
\end{array}\right]
$$

3. Menentukan koordinat objek dengan menggunakan eigen values dan eigen vector dari matriks Bo.

Dengan menggunakan program python, diperoleh eigen values dan eigen vector sebagai berikut:

Eigen Values

$\lambda_{1}=4840.402$

$$
\lambda_{31}=-2.09598825 \mathrm{E}-12
$$

$\lambda_{2}=934.764$

$$
\lambda_{32}=-2.43812956 \mathrm{E}-12
$$

$\lambda_{3}=558.067$

$\lambda_{33}=-2.51862327 \mathrm{E}-12$

$\lambda_{4}=115.666$

$\lambda_{34}=-2.83925237 \mathrm{E}-12$

$\lambda_{5}=75.451$

$$
\lambda_{35}=-3.66201045 \mathrm{E}-12
$$

.....

\section{Eigen Vector}

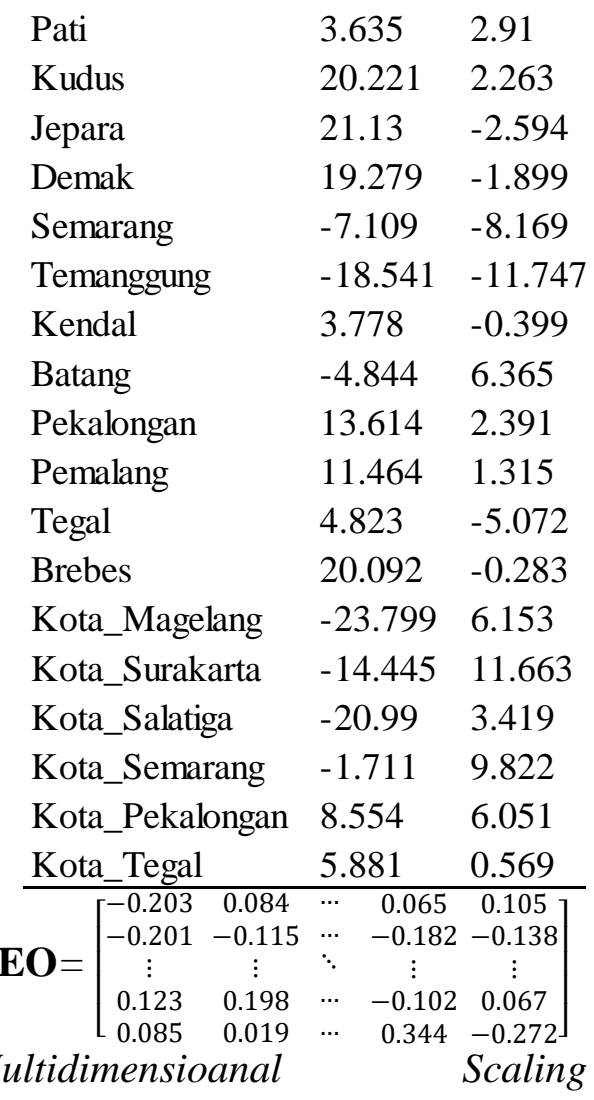

menggunakan 2 dimensi supaya muda diintepretasikan. Oleh karena itu dipilih 2 eigen values positif terbesar dari matriks Bo adalah $\lambda_{1}=$ 4840.402 dan $\lambda_{2}=934.764$. Selanjutnya menentukan titik 
koordinat, dilakukan dengan pengambilan eigen vector yang berkorespondensi dengan eigen values yang terpilih.

Tabel 1. Koordinat titik objek

\begin{tabular}{lrr}
\hline \multirow{2}{*}{ Nama Objek } & \multicolumn{2}{c}{ Koordinat } \\
\cline { 2 - 3 } & \multicolumn{1}{c}{1} & \multicolumn{1}{c}{2} \\
\hline Cilacap & -14.115 & 2.579 \\
Banyumas & -14.011 & -3.522 \\
Purbalingga & -3.277 & 0.688 \\
Banjarnegara & 0.226 & 1.445 \\
Kebumen & -3.753 & -6.067 \\
Purworejo & -16.522 & -6.003 \\
Wonosobo & -4.297 & -8.417 \\
Magelang & -6.273 & 2.756 \\
Boyolali & 6.549 & -4.102 \\
Klaten & 0.149 & -3.717 \\
Sukoharjo & -2.739 & 4.191 \\
Wonogiri & 6.256 & 6.927 \\
Karanganyar & -4.748 & 1.988 \\
Sragen & -3.442 & -4.421 \\
Grobogan & 11.804 & -0.918 \\
Blora & -1.801 & -2.459 \\
Rembang & 8.962 & -3.706 \\
\hline
\end{tabular}

Dari koordinat yang diperoleh pada Tabel 1 selanjutnya dibentuk plot objek seperti pada Gambar 1. Terdapat empat kuadran pada grafik, dengan sebaran objek sebagai berikut:

1. Kuadran 1 (kiri atas): Cilacap, Purbalingga, Magelang, Sukoharjo, Karanganyar, Batang, Kota Magelang, Kota Surakarta, Kota Salatiga, Kota Semarang.

2. Kuadran II (kanan atas): Banjarnegara, Wonogiri, Pati, Kudus, Pekalongan, Pemalang, Kota Pekalongan, Kota Tegal

3. Kuadran III (kiri bawah): Banyumas, Kebumen, Purworejo, Wonosobo, Sragen, Blora, Semarang, Temanggung

4. Kuadran IV (kanan bawah): Boyolali, Klaten, Grobogan, Rembang, Jepara, Demak, Kendal, Tegal, Brebes

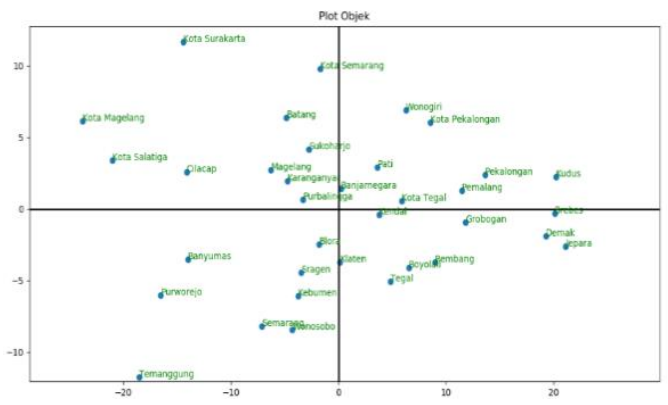

Gambar 1. Preceptual Map Objek (Kabupaten/Kota)

4. Menentukan matriks Dv (D variabel) dengan jarak euclidean

Hasil jarak Euclidean dari matriks Dv7x7:

Hasil jarak Euclidean dari matriks Dv7x7:

$\mathbf{D v}=$

$$
\left[\begin{array}{ccccc}
0 & 37.078 & \cdots & 292.889 & 40.089 \\
37.078 & 0 & \cdots & 315.393 & 42.938 \\
\vdots & \vdots & \ddots & \vdots & \vdots \\
292.889 & 315.393 & \cdots & 0 & 282.674 \\
40.089 & 42.938 & \cdots & 282.674 & 0
\end{array}\right]
$$

Berdasarkan hasil tersebut, matriks jarak Dv menunjukkan MOW (Metode Operasi Wanita) dan Kondom menghasilkan jarak yang dekat dengan metode kontrasepsi yang lainnya menghasilkan jarak sebesar 19.879. Hasil tersebut mengindikasikan MOW dan kondom mempunyai kesamaan dalam hal jumlah penggunanya. Sedangkan MOP (Metode Operasi Pria) dan suntikan memiliki jarak terjauh diantara metode kontrasepsi yang lain menghasilkan jarak sebesar 340.227. Hasil tersebut mengindikasikan MOP dan suntikan memiliki ketakmiripan dalam hal jumlah penggunanya.

5. Menentukan matriks Bv

Diperoleh hasil matriks Bv:

BV $=$

$\left[\begin{array}{llllll}1511.272 & 1593.993 & \cdots & -8032.05 & 400.5826\end{array}\right]$

$\begin{array}{llllll}1593.991 & 3051.513 & \cdots & -14106.3 & 1052.422\end{array}$

$\left[\begin{array}{ccccc}\vdots & \vdots & \ddots & \vdots & \vdots \\ -8032.05 & -14106.3 & \cdots & 68208.37 & -5399.64 \\ 400.5834 & 1052.424 & \cdots & -5399.65 & 897.0458\end{array}\right]$ 
6. Menentukan koordinat variable dengan menggunakan eigen values dan eigen vector matriks $\mathbf{B v}$.

Dengan menggunakan sintaks program Python diperoleh nilai eigen dan vektor eigen sebagai berikut:

Eigen Values

$\lambda_{1}=83294.0064$

$\lambda_{2}=1375.45276$

$\lambda_{3}=655.393739$

$\lambda_{4}=431.358692$

$\lambda_{5}=95.9227687$

$\lambda_{6}=44.4408919$

$\lambda_{7}=-1.35964087 \mathrm{E}-12$

Eigen Vector

$\mathbf{V E V}=\left[\begin{array}{ccccc}0.106 & -0.392 & \cdots & 0.280 & -0.378 \\ 0.188 & 0.126 & \cdots & -0.717 & -0.378 \\ \vdots & \vdots & \ddots & \vdots & \vdots \\ -0.905 & 0.136 & \cdots & 0.037 & -0.378 \\ 0.072 & 0.316 & \cdots & -0.051 & -0.378\end{array}\right]$

Multidimensioanal Scaling

menggunakan 2 dimensi supaya muda diintepretasikan. Oleh karena itu dipilih 2 eigen values positif terbesar dari matriks $\mathbf{B v}$ adalah $\lambda_{1}=$ 83294.0064 dan $\lambda_{2}=1375.45276$. Selanjutnya adalah menentukan koordinat menggunakan eigen values dan eigen vector.

Tabel 2. Koordinat Titik Variabel

\begin{tabular}{lrr}
\hline \multirow{2}{*}{ Nama } & \multicolumn{2}{c}{ Koordinat } \\
\cline { 2 - 3 } Variabel & 1 & 2 \\
\hline IUD & 30.506 & -14.543 \\
MOW & 54.188 & 4.691 \\
MOP & 78.885 & 11.648 \\
Kondom & 67.133 & 9.056 \\
Implan & 9.685 & -27.598 \\
Suntikan & -261.1 & 5.027 \\
Pil & 20.707 & 11.719 \\
\hline
\end{tabular}

Dari koordinat yang diperoleh pada Tabel 2 selanjutnya dibentuk plot variabel seperti pada Gambar 2. Terdapat empat kuadran pada grafik, dengan sebaran objek sebagai berikut

1. Kuadran I (kiri atas): Suntikan

2. Kuadran II (kanan atas): Pil, MOP, Kondom, MOW.

3. Kuadran III (kiri bawah): -
4. Kuadran IV (kanan1bawah): IUD, Implan

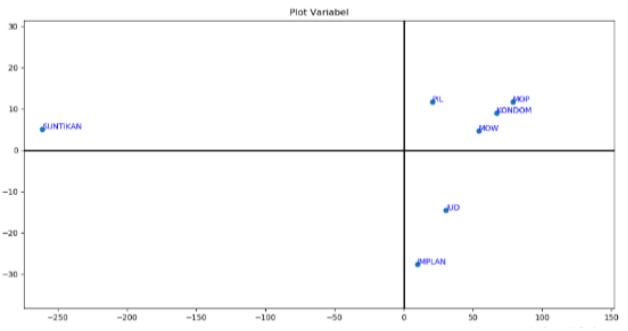

Gambar 2. Preceptual Map Variabel (Metode Kontrasepsi)

7. Menggabungkan perceptual map objek dan preceptual variabel kedalam satu perceptual map seperti pada Gambar 3.

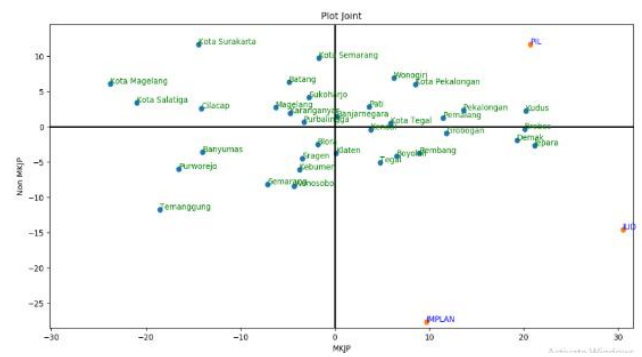

Gambar 3. Preceptual Map Joint

1. Kuadran I (kiri atas): Cilacap, Purbalingga, Magelang, Sukoharjo, Karanganyar, Batang, Kota Magelang, Kota Surakarta, Kota Salatiga, Kota Semarang merupakan kelompok Kabupaten/Kota dengan karakteristik penggunaan alat kontrasepsi non jangka panjang.

2. Kuadran II (kanan atas): Banjarnegara, Wonogiri, Pati, Kudus, Pekalongan, Pemalang, Kota Pekalongan, Kota Tegal merupakan kelompok Kabupaten/Kota dengan tingginya penggunaan metode kontrasepsi jangka pendek dan jangka panjang. Metode kontrasepsi Pil yang cenderung dipakai pada Kabupaten/Kota yang terletak di kuadran II ini. 
3. Kuadran III (kiri bawah): Banyumas, Kebumen, Purworejo, Wonosobo, Sragen, Blora, Semarang, Temanggung merupakan kelompok Kabupaten/Kota dengan rendahnya penggunaan alat kontrasepsi jangka pendek maupun jangka panjang.

4. Kuadran IV (kanan bawah): Boyolali, Klaten, Grobogan, Rembang, Jepara, Demak, Kendal, Tegal, Brebes merupakan kelompok Kabupaten/Kota dengan karakteristik penggunaan alat kontrasepsi jangka panjang. Alat kontrasepsi IUD yang cenderung dipakai pada Kabupaten/Kota yang terletak di kuadran IV ini.

8. Menghitung disparaties matriks $\widehat{D}_{35 \times 35}$ Hasil matriks $\widehat{\boldsymbol{D}}$ menggunakan GUI adalah sebagai berikut:

$$
\widehat{\boldsymbol{D}}=\left[\begin{array}{ccccc}
0 & 6.102 & \cdots & 22.933 & 20.097 \\
6.102 & 0 & \cdots & 24.511 & 20.307 \\
\vdots & \vdots & \ddots & \vdots & \vdots \\
22.933 & 24.511 & \cdots & 0 & 6.100 \\
20.097 & 20.307 & \cdots & 6.100 & 0
\end{array}\right]
$$

9. Menghitung nilai Stress

$$
\begin{aligned}
& \text { Stress }=\sqrt{\frac{7541.783}{419735316.857}}=0.0042 \text { atau } \\
& 0.4 \% \text {. }
\end{aligned}
$$

Hal ini menunjukkan bahwa dimensi 2 dapat digunakan dengan sangat baik karena Stress masuk termasuk kriteria sempurna.

\section{Penyusunan Graphical User Interface Python}

1. Import Packages

Packages utama yang digunakan dalam penyusunan GUI adalah Tkinter. Tkinter merupakan salah satu GUI yang dapat memberikan kemudahan dalam pembuatan program berbasis grafis. Sementara packages yang digunakan untuk analisis Multidimensional Scaling metrik yaitu filedialog, pandas, sklearn, numpy, matplotlib, pillow

2. Membuat sintaks awal GUI
Langkah kedua dalam perancangan GUI pada python 3.8 adalah membuat sintaks seperti judul, icon, ukuran dan background.

3. Membuat Widget GUI

Widget yang dipakai dalam penelitian ini adalah Button, Text atau TextBox, dan Toplevel.

4. Membuat Perintah Untuk Widget

Widget perlu disisipkan perintah perintah supaya dapat difungsikan sesuai perintah yang diinginkan. Berikut hasil pemrograman python berdasarkan tahapan yang telah dilakukan.

\section{KESIMPULAN}

1. Telah diperoleh aplikasi berbasis Graphycal User Interface (GUI) yang mempermudah pengguna untuk melakukan komputasi analisis Multidimensional Scaling metrik sesuai dengan algoritma yang telah dirancang.

2. Nilai stress yang didapat adalah 0.0042 atau $0.4 \%$ mengindikasi-

kan perceptual map Multidimensiona $l$ Scaling dalam kriteria sempurna. Sehingga dapat diartikan bahwa dimensi 2 dapat digunakan dengan sangat baik.

3. Kuadran I seperti Cilacap, Purbalingga, Magelang, Sukoharjo, Karanganyar, Batang, Kota Magelang, Kota Surakarta, Kota Salatiga, Kota Semarang merupakan kelompok Kabupaten/Kota dengan karakteristik penggunaan metode kontrasepsi non jangka panjang. Kabupaten/ Kota yang terdapat di kuadran II yaitu Banjarnegara, Wonogiri, Pati, Kudus, Pekalongan, Pemalang, Kota Pekalongan, Kota Tegal merupakan kelompok Kabupaten/Kota dengan tingginya penggunaan metode kontrasepsi jangka pendek dan jangka panjang. Metode kontrasepsi Pil yang cenderung dipakai pada 
Kabupaten/Kota yang terletak di kuadran II ini. Kabupaten/ Kota yang terdapat di kuadran III yaitu Banyumas, Kebumen, Purworejo, Wonosobo, Sragen, Blora, Semarang, Temanggung merupakan kelompok Kabupaten/Kota dengan rendahnya penggunaan metode kontrasepsi jangka pendek maupun jangka panjang. Kabupaten/ Kota yang terdapat di kuadran IV yaitu Boyolali, Klaten, Grobogan, Rembang, Jepara, Demak, Kendal, Tegal, Brebes merupakan kelompok Kabupaten/Kota dengan karakteristik penggunaan alat kontrasepsi jangka panjang. Alat kontrasepsi IUD yang cenderung dipakai pada Kabupaten/Kota yang terletak di kuadran IV ini.

4. Hasil pemetaan menunjukkan sebanyak 28,57\% Kabupaten/Kota masuk ke kuadran I; 22,86\% kuadran II; 22,86\% kuadran III; $25,71 \%$ kuadran IV. Persentase tertinggi menunjukkan kuadran I dimana Kabupaten/Kota tersebut masih rendah penggunaan MKJP, sehingga pelayanan KB difokuskan pada wilayah MKJP yang rendah yaitu Kabupaten/Kota yang terletak pada kuadran I dan III.

\section{DAFTAR PUSTAKA}

[1] Cicih, L. H. 2019. Info Demografi. Jakarta: BKKBN

[2] BKKBN. 2018. Narasi Rapat Pengendalian Program dan Anggaran Data s/d Bulan Oktober 2018. Semarang: BKKBN.

[3] BKKBN. 2017. Laporan

[4] Nafisah, S., dan Setiawan, T. H. 2019. Penerapan Analisis Multidimensional Scaling pada Pemetaan Karakteristik Kemiskinan di Provinsi Banten. Jurnal Statistika dan Matematika Vol.
1, No. 2: Hal. 46-59. Instansi

Pemerintah 2016 Badan

Kependudukan dan Keluarga

Berencana Nasional. Jakarta:

BKKBN.

[5] Aplikasi.bkkbn.go.id. (2019, Desember). Laporan DALLAP. Diakses pada 13 Februari 2020, dari https://aplikasi.bkkbn.go.id/sr/DAL LAP/Laporan2013/ Bulanan/Dalap 2013Tabel15.aspx.

[6] Borg, I. dan Groenen, P.J.F. 2005. Modern Multidimensional Scaling Theory and Applications Second Edition. New York: Springer.

[7] Puspindes. n.d. Buku Panduan Pemrograman Python. Pemalang: Dinas Pemberdayaan Masyarakat Dan Pemerintahan Desa Kabupaten Pemalang.

[8] Python. tanpa tahun. What is Python? Executive Summary. Diakses pada 06 Mei 2020, dari http://www.python.org/doc/essays/ blurb.

[9] Sihombing, D. I. 2016. Analisis Multivariat Dengan Metode Multidimensional Scalling Untuk Peningkatan Proses Belajar Mengajar (PBM) Di FKIP UHN Medan. Medan: Lembaga Penelitian Universitas HKBP Nommensen Medan. 